\title{
Ground vegetation monitoring in Swiss forests: comparison of survey methods and implications for trend assessments
}

\author{
Anne Thimonier • Peter Kull • Walter Keller • \\ Barbara Moser · Thomas Wohlgemuth
}

Received: 5 March 2010 / Accepted: 29 September 2010 / Published online: 4 November 2010

(C) Springer Science+Business Media B.V. 2010

\begin{abstract}
At Swiss long-term forest ecosystem research sites, ground vegetation was assessed during the period 1994-2003/2008 following two approaches: (1) visual assessment of the cover of species occurring in sixteen $1 \mathrm{~m}^{2}$ quadrats, distributed over a $43 \times 43 \mathrm{~m}$ area, and (2) phytosociological relevés in concentric circular plots of 30,200 , and $500 \mathrm{~m}^{2}$. We first compared the two approaches with respect to diversity assessment. The number of species recorded in the 16 quadrats was in general higher than in the $30 \mathrm{~m}^{2}$ plot and it represented $42 \%$ to $108 \%$ of the number of species recorded in the $500 \mathrm{~m}^{2}$ plot. In a second step, we tested whether any temporal trends were apparent. In a few cases, a decrease or increase in Landolt's mean indicator values for light, nitrogen availability, soil $\mathrm{pH}$, soil moisture, or temperature was found to be significant. However, these changes were usually restricted to one approach or one area. The only clear trend was detected
\end{abstract}

\footnotetext{
A. Thimonier $(\varangle)$ · P. Kull · W. Keller · B. Moser .

T. Wohlgemuth

WSL-Swiss Federal Institute for Forest, Snow and Landscape Research, Zürcherstrasse 111, 8903 Birmensdorf, Switzerland e-mail: anne.thimonier@wsl.ch

Present Address:

P. Kull

Landwirtschaft und Wald, Centralstrasse 33, 6210 Sursee, Switzerland
}

in an unmanaged former coppice beech stand, for which all survey approaches indicated canopy closure. At another site, vegetation reacted to the local opening of the canopy following windthrow. In a third step, we compared the leaf area index (LAI), measured with an LAI-2000 instrument (Licor, Inc.) over each quadrat, with the indicator value of the vegetation for light $(L)$. Within a site, there was no clear relationship between LAI and $L$ values per quadrat. In contrast, across all sites, the relationship between LAI and $L$, averaged per site for all available years, was highly significant.

Keywords Ground vegetation • Multiple quadrat approach • Phytosociological relevé • Species diversity $\cdot$ Ecological indicator values $\cdot$ LAI

\section{Introduction}

Ground vegetation is a key component of forest ecosystems. It contributes to the biological diversity of the forest ecosystem, plays an important functional role in the water and nutrient cycle, and interacts strongly with other biota, as habitat or source of nutrients. In addition, ground vegetation is a powerful bio-indicator of the environment, as the species composition of a plant community reflects the ecological conditions at a given site and at a given time (Diekmann 2003). The long-term study of vegetation dynamics thus 
allows changes in the status of a major component of the forest ecosystems to be documented on the one hand, and can reveal ongoing changes in environmental conditions on the other hand (e.g., Diekmann et al. 1999; Thimonier et al. 1992; van Dobben et al. 1999). Vegetation surveys are therefore core assessments in the intensive forest monitoring program (Level II) implemented within the International Co-operative Programme on Assessment and Monitoring of Air Pollution Effects on Forests (ICP Forests). The ICP Forests Level II network gathers around 800 sites across 39 European countries (Campetella et al. 2005-2006; de Vries et al. 2003b; Seidling 2005; Seidling and Fischer 2008).

Because the quality of vegetation assessments is essential in studies aiming at detecting changes on the spatial or temporal scale, major efforts have been invested in order to reduce measurement errors, both at the European level and in the individual countries participating in ICP Forests (e.g., Allegrini et al. 2009; Archaux et al. 2009). Sources of errors in vegetation assessments include the misidentification and the overlooking of plant species by the observers (e.g., Archaux et al. 2009; Klimeš et al. 2001), as well as the subjectivity of the observers when estimating the cover or abundance of each species present (e.g., Klimeš 2003; Sykes et al. 1983). Such errors have been documented even when professional, experienced botanists were involved in vegetation assessments. The magnitude of these observer-related sampling errors may be influenced by the size of the vegetation plot, i.e., the area that is sampled, as was shown by e.g. Klimeš et al. (2001), Klimeš (2003), Allegrini et al. (2009), and Otýpková (2009). The number of observers involved in a vegetation census also influences the quality of the assessment, as combining records of two observers was shown to increase substantially the number of species recorded compared to the list established by a single observer (e.g., Klimeš et al. 2001). Lastly, the time dedicated to a vegetation census is critical; Archaux et al. (2006), for example, demonstrated that the number of species recorded increased semi-logarithmically with the sampling time.

In Switzerland, 17 ICP Forests Level II sites were established in the mid-1990s or later, within the framework of the Swiss long-term forest ecosystem research program (LWF) (Cherubini and Innes 2000). Ground vegetation surveys were repeatedly carried out during the period 19942003 at the LWF sites, using two approaches: (1) visual assessment of the cover of each species (in $\%$ ) occurring in $1 \mathrm{~m}^{2}$ vegetation quadrats and (2) visual assessment of the abundance-dominance of each species recorded in larger plots (up to $500 \mathrm{~m}^{2}$ ), using the Braun-Blanquet scale. Both approaches are common in monitoring studies, but they are rarely implemented in parallel at the same sites. In this paper we will (1) compare the two methods in terms of diversity assessment and ecological site classification; (2) assess firstly whether any temporal changes in the floristic composition of the plant communities are apparent, secondly whether both methods lead to consistent conclusions, and thirdly whether observer effects can be identified; and (3) relate the spatial and temporal variation of the ground vegetation to that of light conditions, which are reflected by the leaf area index (LAI) values measured over time with the Licor LAI-2000.

\section{Material and methods}

Site description

The 17 LWF sites investigated are distributed across the main geographical regions of Switzerland (Table 1). Elevations range from $480 \mathrm{~m}$ a.s.l. in the Swiss Plateau to $1,900 \mathrm{~m}$ a.s.l. in the Alps, and types of soils range from calcareous soils to podzols (Walthert et al. 2003). Two important criteria for site selection at the beginning of the monitoring program (Innes 1995) were the homogeneity of the forest site type, as defined in the Swiss forest classification (Ellenberg and Klötzli 1972) and structural uniformity. The forest stands usually consist of one main tree species. The most represented tree species include beech (Fagus sylvatica L.) at six sites and Norway spruce (Picea abies (L.) Karst.) at four sites. The other main tree species, represented in one or two LWF stands only (Table 1), are oak (Quercus robur L. and Quercus cerris L.), pine (Pinus sylvestris L., Pinus cembra L., and Pinus mugo Turra), and silver fir (Abies alba Mill.). 


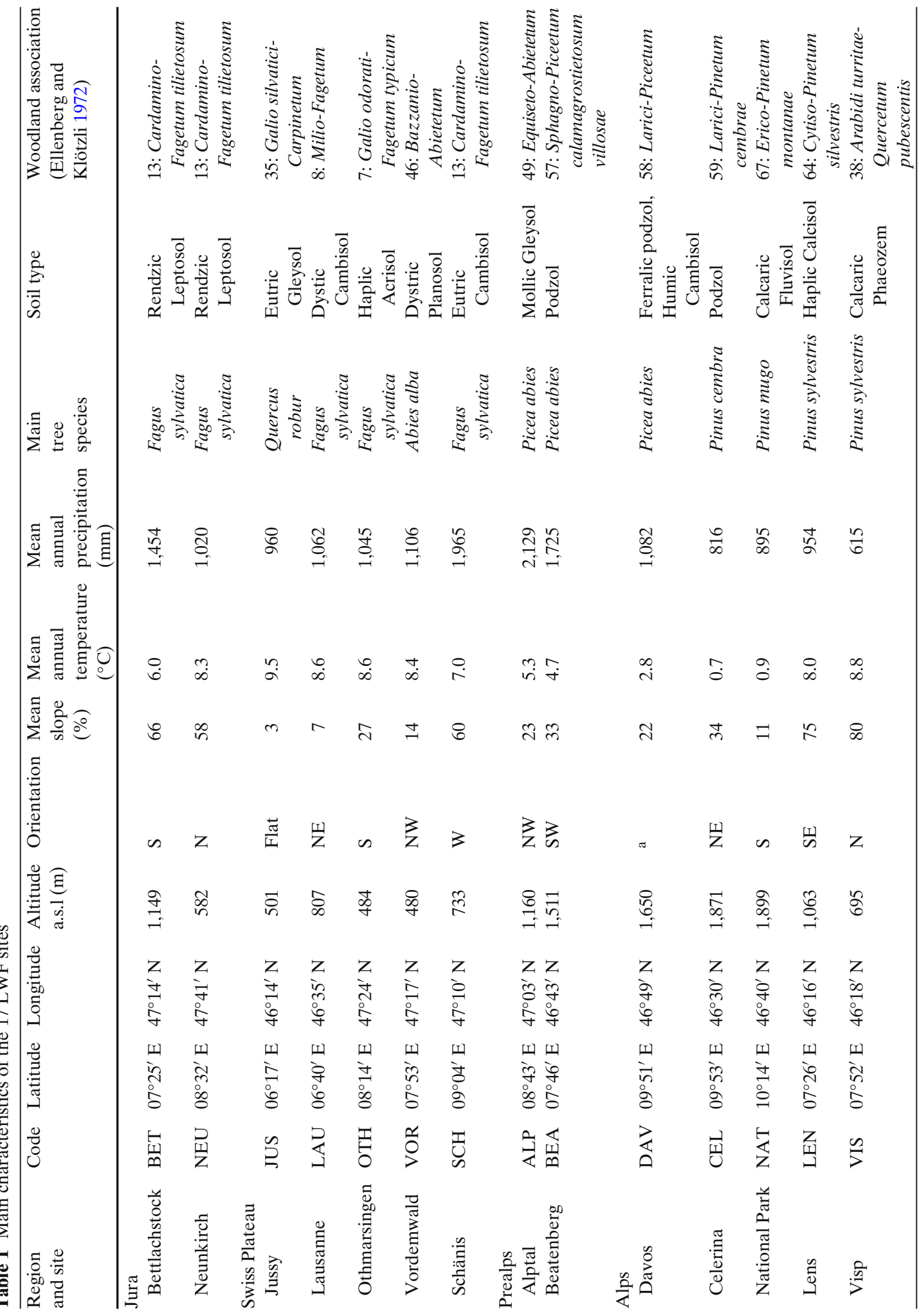




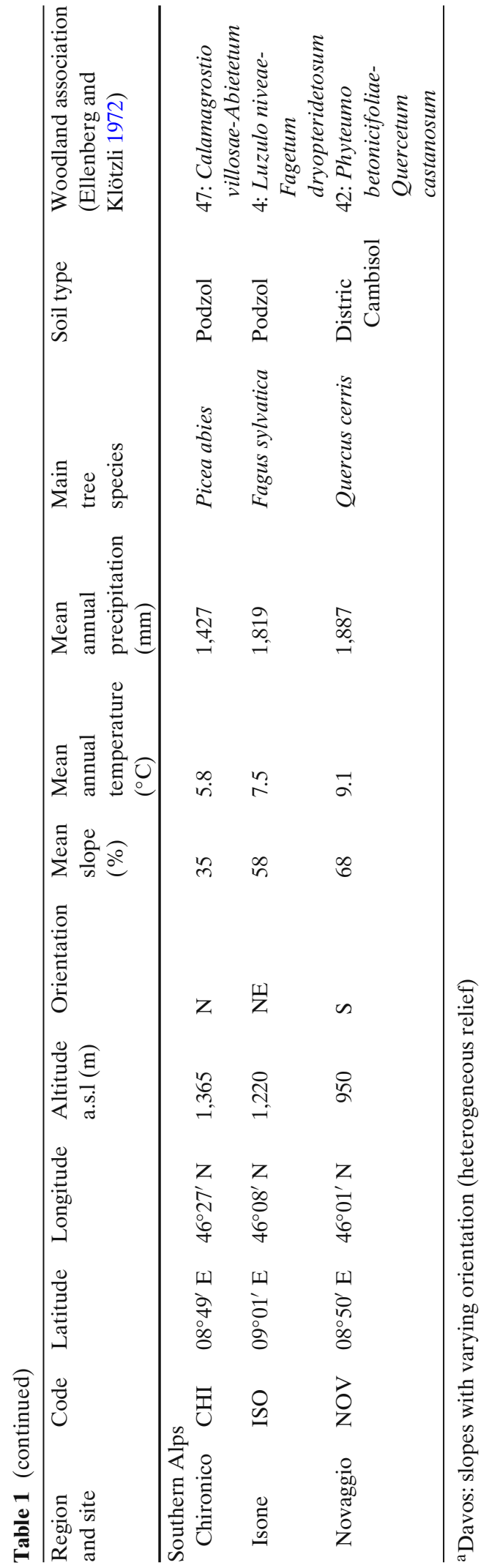

\section{Vegetation surveys}

On all sites, ground vegetation was surveyed following two approaches: phytosociological relevés and the multiple quadrat approach. Phytosociological relevés were made in one or two circular plots with concentric sub-plots of 30, 200, and $500 \mathrm{~m}^{2}$, with estimation of abundancedominances of all species in the moss, herb, shrub, and tree layers using the Braun-Blanquet scale (Braun-Blanquet 1964). Only mosses growing on soil were recorded. The multiple quadrat approach refers to 16 intensive vegetation quadrats of $1 \mathrm{~m}^{2}$ that are distributed over a $43 \times 43 \mathrm{~m}$ area and arranged along a systematic grid of $11 \mathrm{~m}$ mesh size (Fig. 1). The design at Davos site (DAV; for site codes see Table 1) differs from the other LWF sites, with four $43 \times 10 \mathrm{~m}$ rows of four $1 \mathrm{~m}^{2}$ quadrats distributed over the whole site rather than being adjacent over a square grid. The cover

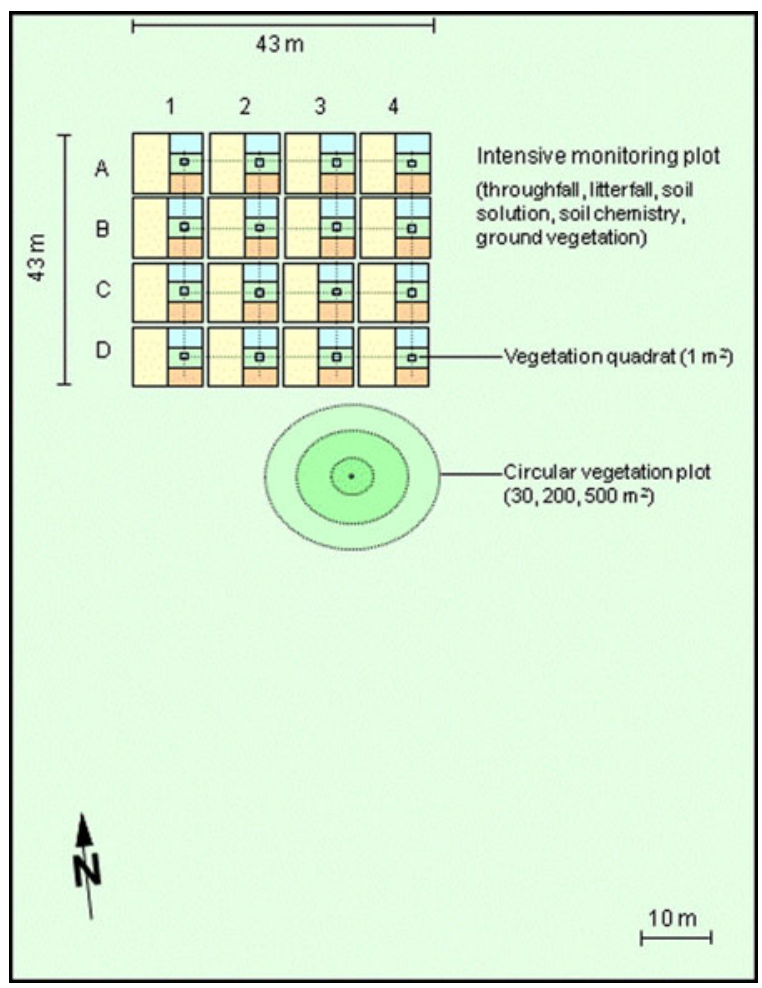

Fig. 1 Location of the sixteen $1 \mathrm{~m}^{2}$ quadrats, systematically arranged along a square grid of $11 \mathrm{~m}$ mesh size, and the circular phytosociological relevé plot with concentric subplots of 30,200 , and $500 \mathrm{~m}^{2}$ at Novaggio 
of all species belonging to the moss, herb, shrub, and tree layers was estimated in \%.

Positions of the quadrats are permanently marked by plastic stakes at two opposite corners, on which a $1 \times 1 \mathrm{~m}$ aluminium frame, subdivided into $10 \times 10$ cells, is installed during the census. Centers of the circular relevé plots are permanently marked by wooden stakes. During the relevé, the limits of the circular plots are marked using temporary plastic stakes in four cardinal directions. Vegetation surveys at one site were usually carried out on the same day ( \pm 3 days) in summer. Surveys started between 1994 and 1998 (Table 2). All sites were re-assessed in 1999, 2001, and 2003. One exception was the site DAV, which was only recently added to the LWF network, and where vegetation was surveyed only once, in 2008. The same botanist, together with a student, surveyed the vegetation from 1994 to 1999; another botanist, alone, surveyed the vegetation in 2001 and 2003; and a team of two botanists assessed the plots of DAV in 2008. In order to enhance the quality and completeness of the vegetation censuses, as much time as needed was allowed for plot assessments. The nomenclature of vascular plant species follows the Flora Europaea (Tutin et al. 1964-1993).

\section{LAI measurements}

Parallel to the vegetation censuses, the leaf area index of the forest stand was also repeatedly assessed with an LAI-2000 plant canopy analyzer (LiCor, Inc., Lincoln, NE, USA). LAI measurements were performed directly above the 16 quadrats, usually on the same day. Two crosscalibrated LAI-2000 instruments were used to record in parallel diffuse radiation below the canopy and in a nearby open area. Detailed information on the acquisition and processing of the radiation measurements with the LAI-2000 at the LWF sites can be found in Thimonier et al. (2010).

\section{Data analysis}

The vegetation data were first screened for possible species identification problems. A few species were identified differently by the first team and the second botanist. For example, Gentiana pur- purea in the first surveys was noted as Gentiana punctata in 2001-2003; Campanula scheuchzeri was later recorded as Campanula rotundifolia, Pyrola minor as Pyrola rotundifolia, and Agrostis stolonifera as Agrostis tenuis. A few probable misidentifications were also detected when consecutive censuses made by the same team or botanist were compared, notably between Rhytidiadelphus loreus and Rhytidiadelphus triquetrus, Thuidium tamariscinum and Hylocomium splendens, and Dryopteris carthusiana and Dryopteris dilatata. For the subsequent analyses, pairs of misidentified species were merged into one single generic name; e.g., G. purpurea and G. punctata were both renamed as Gentiana sp.

The data from the multiple quadrat approach were analyzed at the quadrat level ( $1 \mathrm{~m}^{2}$ plots) and by aggregating the data obtained from all 16 quadrats, hereafter referred to as the $16 \mathrm{~m}^{2}$ plot. When two $500 \mathrm{~m}^{2}$ plots were surveyed at a site, we kept the one closest to the $16 \mathrm{~m}^{2}$ plot for the analysis, except at DAV, where we kept both. All in all, data obtained from 1, 16, 30, 200, and $500 \mathrm{~m}^{2}$ vegetation plots were thus available for the analyses.

The status of ground vegetation in a given year was described using species richness, Shannon's index of diversity, and Landolt's indicator values (Landolt 1977). The species richness of each vegetation plot $\left(1,16,30,200\right.$, and $\left.500 \mathrm{~m}^{2}\right)$ was calculated for each year as the total number of species recorded in the herb and moss layers. The species richness at the site level was calculated as the number of distinct species occurring in the 16 and $500 \mathrm{~m}^{2}$ vegetation plots.

Shannon's index of diversity $\mathrm{H}^{\prime}$ was calculated for each year and each vegetation plot according to Eq. 1:

$H^{\prime}=-\sum_{i=1}^{n}\left(p_{i} \cdot \log _{2} p_{i}\right)$

where $p_{i}$ is the relative abundance of species $i$, calculated as:

$p_{i}=\frac{c_{i}}{\sum_{i=1}^{n} c_{i}}$

where $c_{i}$ is the relative cover of species $i$ and $n$ is the total number of species. 


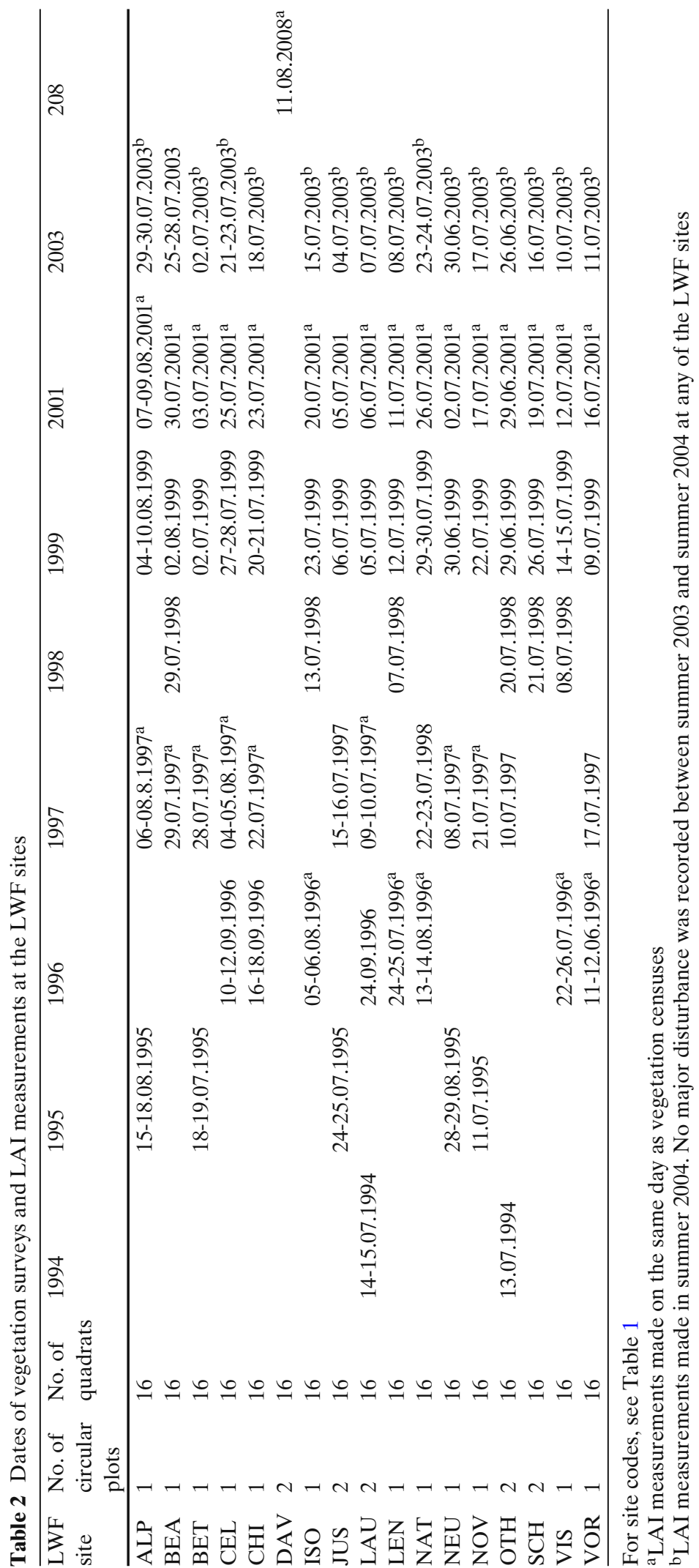


Landolt's indicator values (Landolt 1977) express the ecological range of Swiss plant species with respect to soil nutrient availability (mostly nitrogen, $N)$, soil acidity $(R)$, soil moisture $(F)$, light $(L)$, and temperature $(T)$ on an ordinal fivepoint scale. Synthetic indices of the ecological conditions for each site and for a given year were calculated by averaging the Landolt values of all species recorded in the herb layer, excluding tree seedlings. The calculated indices are unweighted averages, i.e., they are based on presence of species only.

The two survey approaches and the different plot sizes were evaluated against each other by comparing the mean values of species richness, diversity index, and Landolt's ecological values, calculated for each vegetation plot over all measurement years. The coefficients of variation of these means were used to test whether plot size, which directly influences the number of species recorded, had an effect on the range of variation of these indices. We applied the non-parametric signed-rank test (Wilcoxon 1945) on pairs of coefficients of variation calculated for different plot sizes ( 30 versus $500 \mathrm{~m}^{2}$ and 16 versus $500 \mathrm{~m}^{2}$ ).

To detect gradual but steady temporal changes in the number of species, in Shannon's index of diversity and in Landolt's ecological values, we used linear regressions against time. The presence of abrupt changes was assessed visually based on graphic representations of these parameters versus time. Differences were also calculated for each of these parameters using the first and last surveys only. Sørensen's indices of dissimilarity $S$ were calculated to describe changes in the plant species composition in a given vegetation plot between two survey years according to Eq. 2.

$$
S=1-(2 \cdot C) /\left(N_{t 1}+N_{t 2}\right)
$$

where $C$ is the number of species shared in surveys $t 1$ and $t 2, N_{t 1}$ and $N_{t 2}$ are the number of species recorded during survey $t 1$ and survey $t 2$, respectively.

We applied Eq. 2 first to assess changes between two consecutive years, and then between the first and last survey years.

\section{Results}

Species diversity and site conditions

The average number of species per site varied from 17 (at NEU) to 125 (at ALP). In general, the average number of species recorded in the 16 quadrats was higher than the number of species in the $30 \mathrm{~m}^{2}$ circular plot (Fig. 2; one exception, i.e., JUS). On average over all survey years, the number of species in the 16 quadrats represented $42 \%$ (at LEN) to $108 \%$ (at $\mathrm{CHI}$ ) of that recorded in the $500 \mathrm{~m}^{2}$ circular plots, with a median value of $79 \%$ over all plots. The number of species in the $200 \mathrm{~m}^{2}$ plot represented $61 \%$ (at BEA) to $93 \%$ (at VIS) of the corresponding number in the $500 \mathrm{~m}^{2}$ plot. The number of species at the site level was always higher than the number of species in $16 \mathrm{~m}^{2}$ or in $500 \mathrm{~m}^{2}$ (Fig. 2). The largest difference between the species richness at the site level and the number of species recorded in the richest of the two vegetation plots $\left(16\right.$ or $500 \mathrm{~m}^{2}$ ) amounted to 20 species (ALP in 2003).

Average Landolt indicator values calculated for the 16 quadrats and the 30,200 , or $500 \mathrm{~m}^{2}$ circular plots gave consistent information on the ecological conditions at the site (Fig. 3). Coefficients of correlation between the same indicator value obtained from $16,30,200$, and $500 \mathrm{~m}^{2}$, all above 0.89 , were highly significant $(P<0.0001)$. As could be expected, coefficients were slightly higher between the 200 and $500 \mathrm{~m}^{2}$ plots $(r=0.99,0.94$, $0.98,0.99$, and 0.99 for $L, N, R, F$, and $T$, respectively) than between 16 and $500 \mathrm{~m}^{2}(r=0.96$, $0.89,0.95,0.96$, and 0.96 for $L, N, R, F$, and $T$, respectively). The greatest discrepancy between indicator values obtained from 16 and $500 \mathrm{~m}^{2}$ plots was found at BEA (for $N$, Fig. $3 \mathrm{~b}$; and $R$, not shown). At this site, values obtained from $200 \mathrm{~m}^{2}$ plots also differed markedly from those gained from $500 \mathrm{~m}^{2}$ plots. The values obtained from the 30 and $16 \mathrm{~m}^{2}$ plots at VOR and the $30 \mathrm{~m}^{2}$ plot at DAV differed from the values gained from the $500 \mathrm{~m}^{2}$ plot at these two sites (Fig. 3b).

\section{Temporal changes}

The floristic composition of the vegetation plots changed between 1994/1998 and 2003, as indicated 


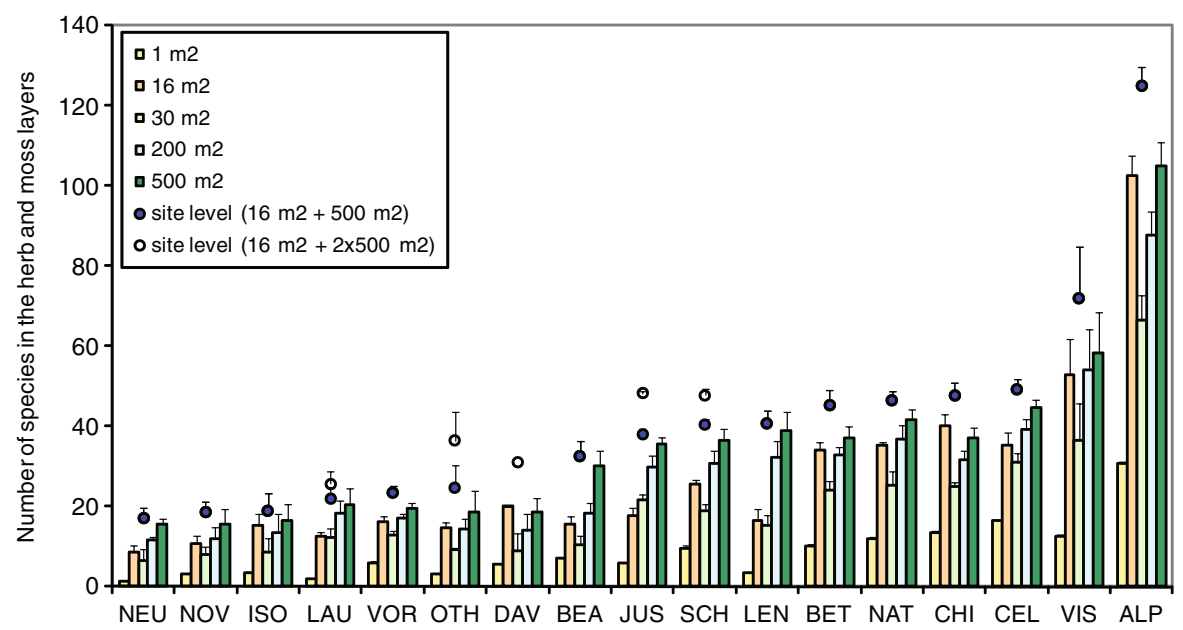

Fig. 2 Number of species (means and standard deviation for all survey years) in the herb and moss layers recorded in the various vegetation plots at 17 LWF sites, sorted in ascending order of species richness at the site level. Species

by Sørensen's indices of dissimilarity. At seven sites (BEA, ISO, JUS, LAU, NAT, NEU, and NOV), dissimilarities between the first and last

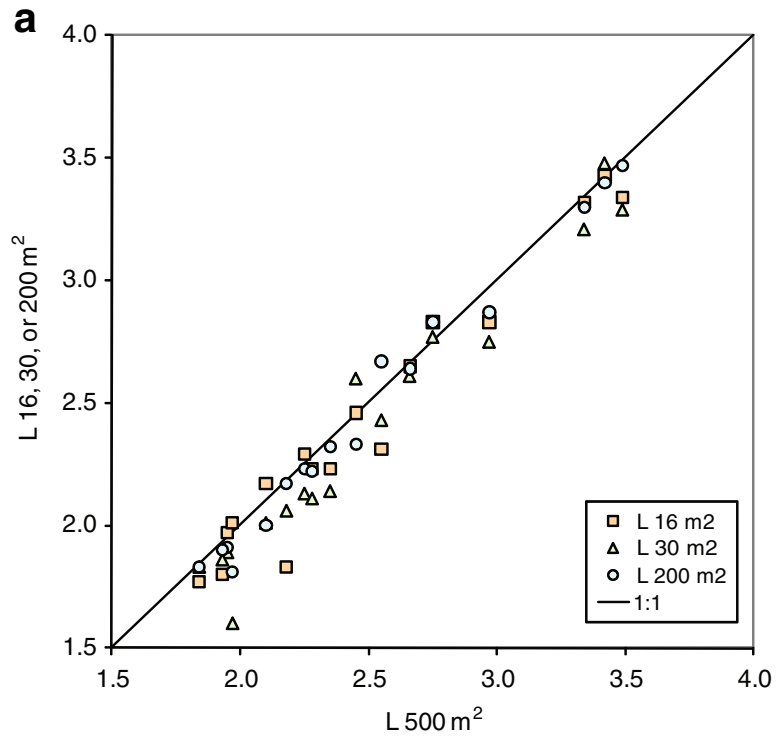

Fig. 3 Comparison of average Landolt indicator values per site ( $n=17$; averages of all survey years) for a light $(L)$ and b nitrogen availability $(N)$ obtained from four vegetation plots $\left(16,30,200\right.$, and $\left.500 \mathrm{~m}^{2}\right)$. Indicator values for the 16 , richness at the site level is defined as the number of distinct species occurring in the 16 and $500 \mathrm{~m}^{2}$ vegetation plots (dark dots $500 \mathrm{~m}^{2}$ plot closest to the $16 \mathrm{~m}^{2}$ plot, open circles data from two $500 \mathrm{~m}^{2}$ plots)

surveys of the monitoring series markedly exceeded the ones calculated for two consecutive years (Fig. 4). The opposite was observed at BET,

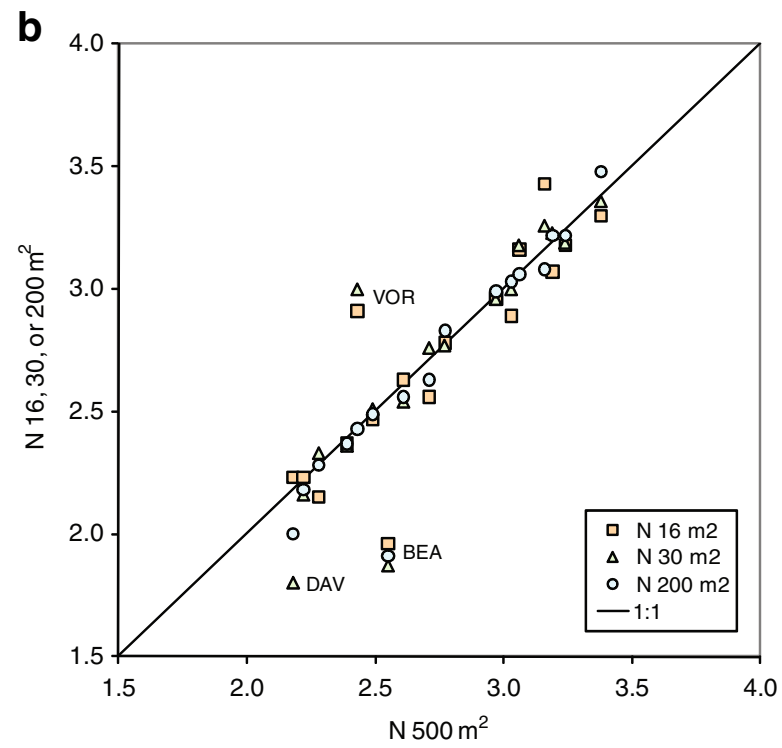

30 , and $200 \mathrm{~m}^{2}$ plots are plotted against the values obtained from the $500 \mathrm{~m}^{2}$ plot, which are considered as reference values 


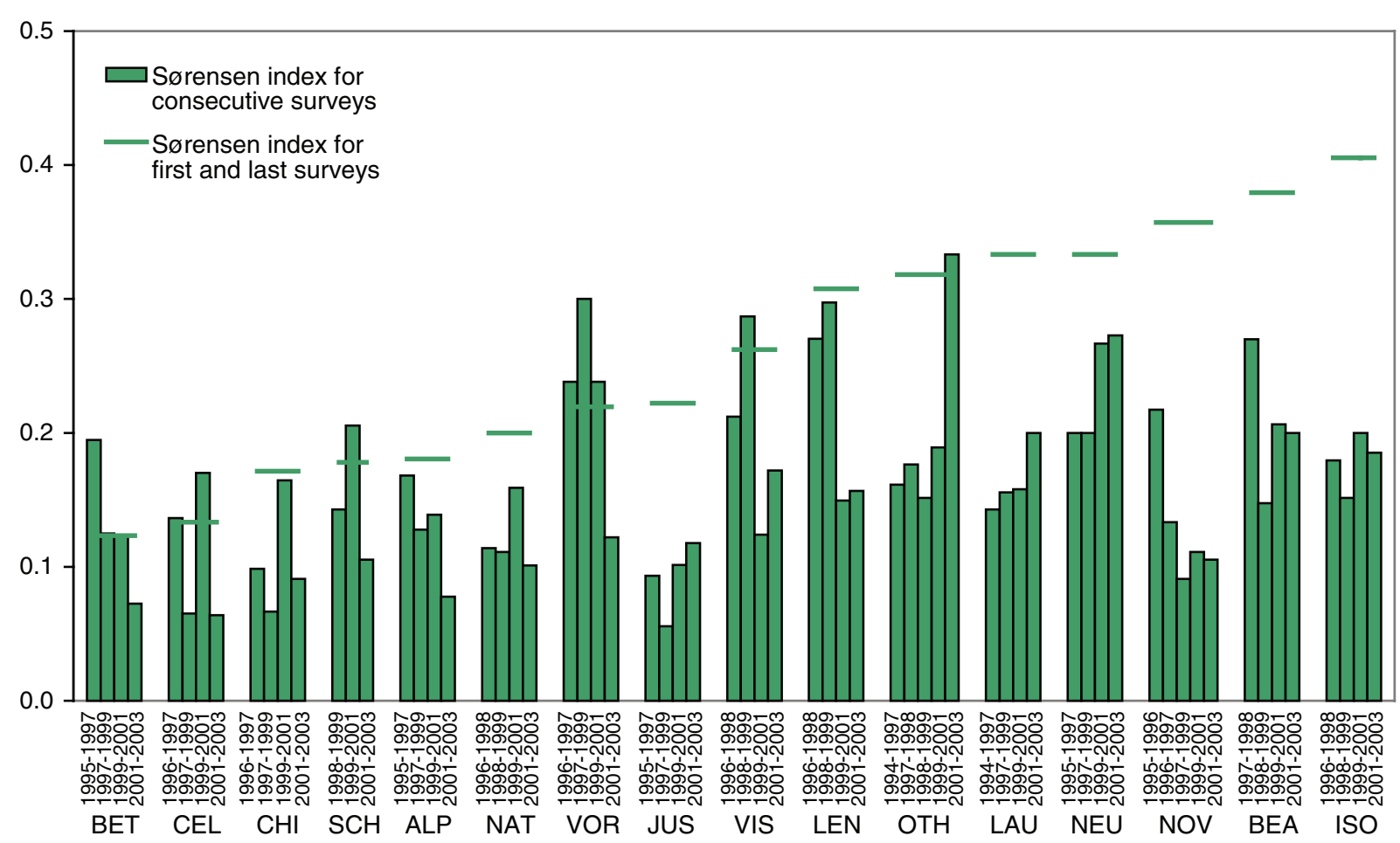

Fig. 4 Sørensen's index of dissimilarity between two consecutive years (bars) and between the first and last survey years (thick line) calculated for the $500 \mathrm{~m}^{2}$ plots. The 16
LWF sites are in rank order of the index calculated for the first and last surveys
CEL, SCH, VIS, and VOR. Sørensen's indices for the period 1999/2001, which corresponds to a change in observers, were not systematically higher than those calculated for other consecutive surveys. There was no clear relationship between the degree of change as indicated by Sørensen's indices and the size of the vegetation plot (not shown).

Similarly, we found no clear effect of plot size on the coefficients of variation of the average Landolt's ecological values calculated over all survey years (not shown). For the number of species, the coefficient of variation tended to be higher for the $30 \mathrm{~m}^{2}$ plot (median value, 11.6\%) than for the other plots (median values, $8.8 \%$, $10.5 \%$, and $8.3 \%$ for the 16,200 , and $500 \mathrm{~m}^{2}$ plots, respectively). The difference between the
30 and the $500 \mathrm{~m}^{2}$ plot was significant at $P<$ 0.05 (Wilcoxon's signed-rank test). The highest coefficients of variation were obtained for the number of species ( $>40 \%$ at NEU and ISO on the $30 \mathrm{~m}^{2}$ plot $)$ and $L\left(29 \%\right.$ at NEU on the $16 \mathrm{~m}^{2}$ plot).

Linear regression versus time revealed no overall pattern in the temporal evolution of the number of species, Shannon's index of diversity, or Landolt's mean ecological values, which varied in all directions depending on the site and plot size. In a few cases, linear regressions indicated a gradual decrease or increase in some of these parameters. Most frequently, these changes related to the light value. However, they were usually restricted to one approach (quadrats or circular plots) or one area (e.g., significant changes found 
Fig. 5 Temporal changes in the average Landolt indicator values for light $(L)$ obtained from three vegetation plots $(16,200$, and $\left.500 \mathrm{~m}^{2}\right)$ at the sites of a Isone (ISO) and $\mathbf{b}$ Neunkirch (NEU). LAI was measured over the 16 quadrats in 1996 and 2004 at ISO, and in 1997, 2001, and 2004 at NEU
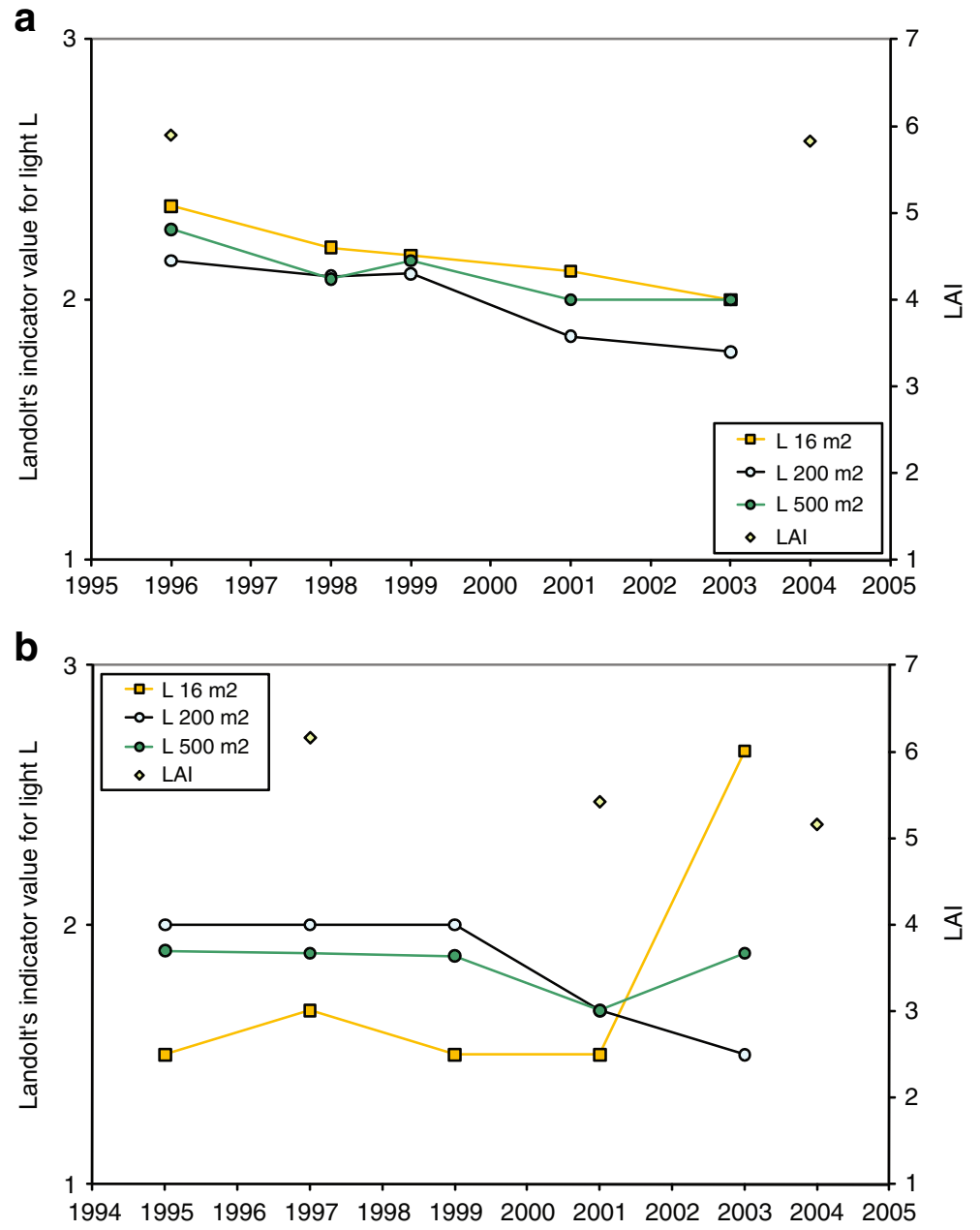

in the $200 \mathrm{~m}^{2}$ but not in the $500 \mathrm{~m}^{2}$ plot). The only clear temporal trends were detected at ISO, an unmanaged former coppice beech stand in the Southern Alps, for which all survey approaches indicated canopy closure (significant decrease in $L$ at $P<0.05$ or lower; Fig. 5a). This linear trend was associated with a decrease in the number of herb and moss species in all vegetation plots (significant at $P<0.10$ or lower), and a decrease in Shannon's index of diversity in all plots as well, except for the $16 \mathrm{~m}^{2}$ plot. At NEU, a beech stand in the Jura, the ground vegetation reacted to the local opening of the canopy following windthrow, which was reflected by a recent and sharp increase in Landolt's mean ecological value for light (Fig. 5b).

Changes in indicator values using the first and last survey years only are shown in Fig. 6 for 16, 200 , and $500 \mathrm{~m}^{2}$ plots. The extreme values for $F$, $L, R$, and $T$ calculated for $16 \mathrm{~m}^{2}$ all concerned NEU. The indicator value for soil acidity $R$ decreased between the first and last survey at most of the sites. This decrease was significant at $P<$ 0.05 for the $16 \mathrm{~m}^{2}$ plots and the $200 \mathrm{~m}^{2}$ plots, and at $P<0.01$ for the $500 \mathrm{~m}^{2}$ plots (Wilcoxon's signed-rank test). 
Fig. 6 Box plots of the changes in the average Landolt indicator values for soil moisture $(F)$, light $(L)$, nitrogen availability $(N)$, soil acidity $(R)$, and temperature $(T)$ between the first and last survey for the 16, 200, and $500 \mathrm{~m}^{2}$ vegetation plots in 16 LWF sites
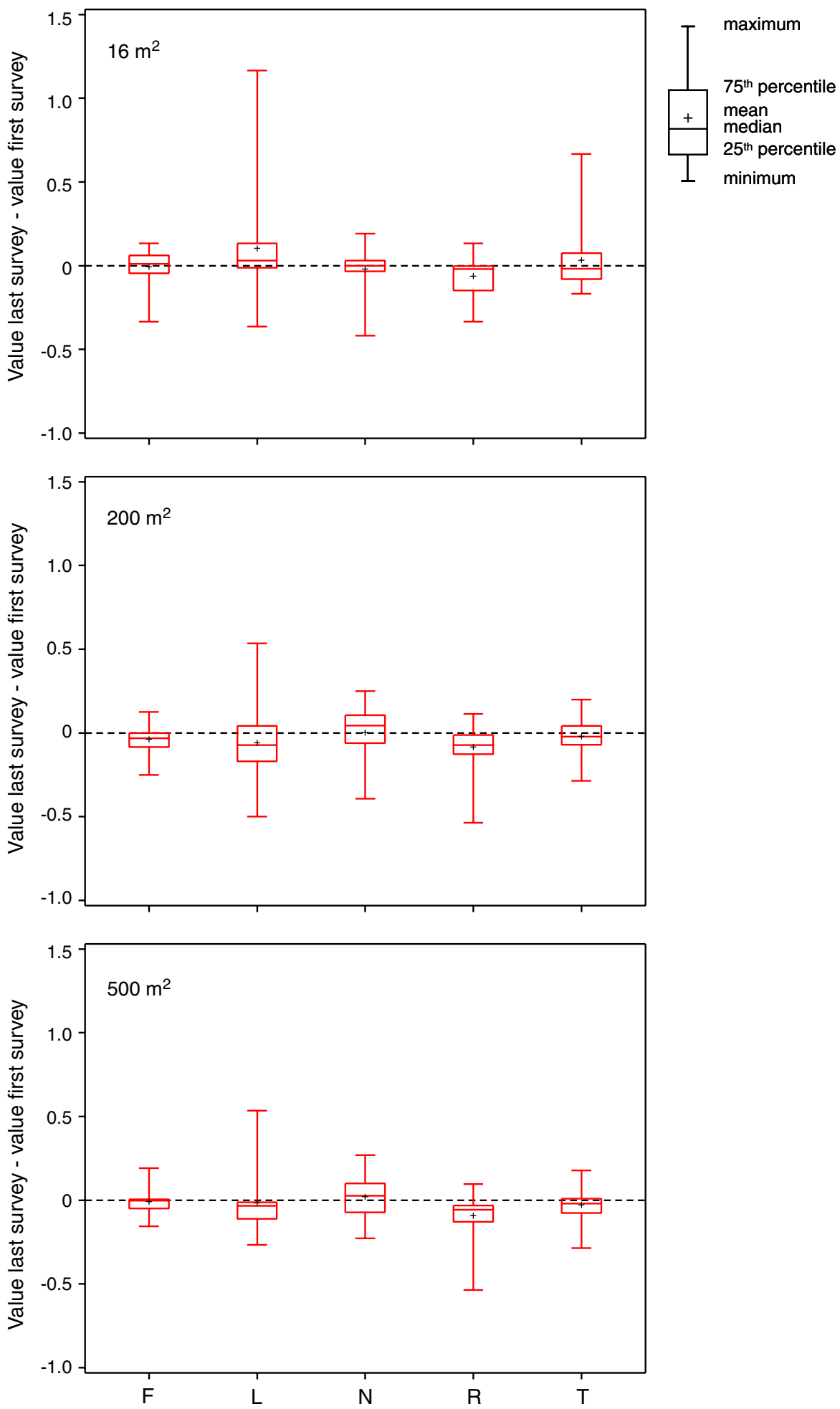


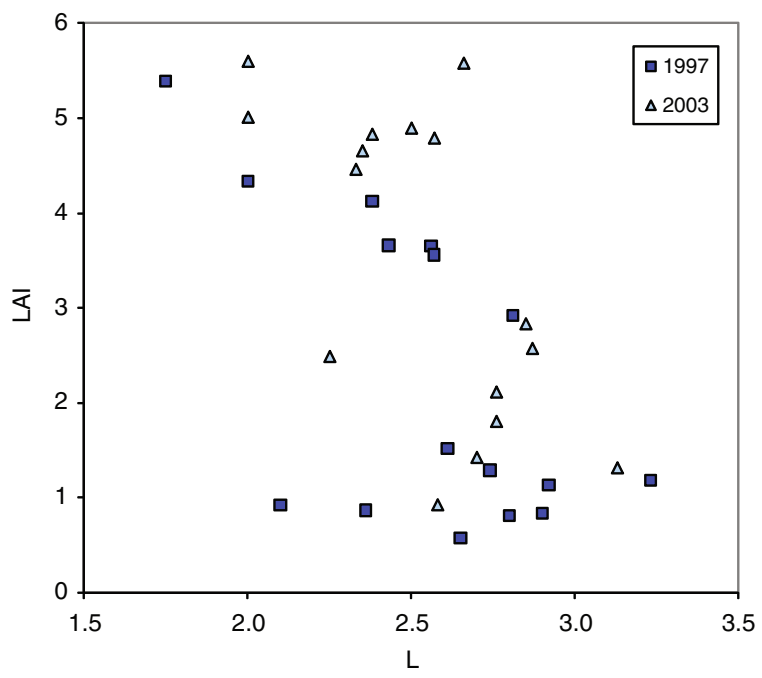

Fig. 7 Site at Alptal (ALP). Relationship between LAI and the average Landolt indicator value for light $L$ at the quadrat level in 1997 and 2003

\section{Light and vegetation}

At a given site, there was no clear relationship between LAI and $L$ or any other Landolt indicator

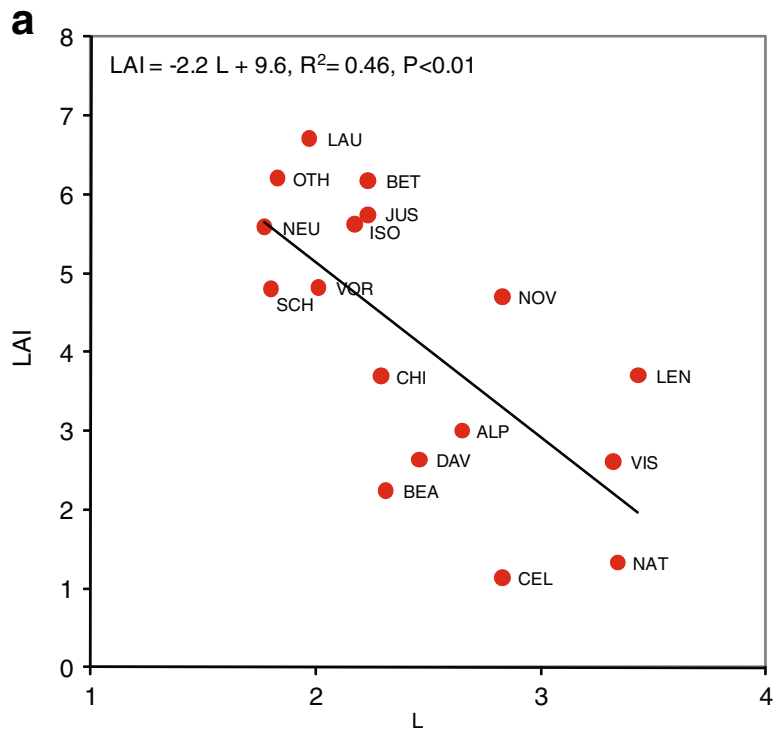

Fig. 8 Relationship between the mean LAI measured with the LAI-2000 and average Landolt indicator values for light $L$ (a) and nitrogen availability $N(\mathbf{b})$. LAI and indi- value calculated per quadrat. One exception was the site ALP, which covered a large gradient of LAI values and had the highest number of species in the herb-layer across all 17 sites $(r=-0.60$, $P<0.05$ between LAI and $L$ in 1997 and $r=$ $-0.64, P<0.01$ in 2003 ; Fig. 7 ).

If all sites were considered, using averaged LAI and indicator values per site for all available years, not only the relationships between LAI and $L$ (Fig. 8a) but also between LAI and $N$ (Fig. 8b) were highly significant. The relationship between $L$ and LAI was stronger and more linear than between $L$ and the diffuse non-interceptance value (not shown), which is calculated by the LAI-2000 and which represents a direct estimate of how much diffuse sky radiation penetrates the canopy.

No overall relationship between changes in LAI and changes in e.g. $L$ or $N$ was detected. At NEU, consistent with the increase in $L$, the mean LAI measured over the 16 quadrats at NEU decreased between 1997 and 2004. However, the decrease in $L$ observed at ISO was not associated with a measurable increase in LAI.

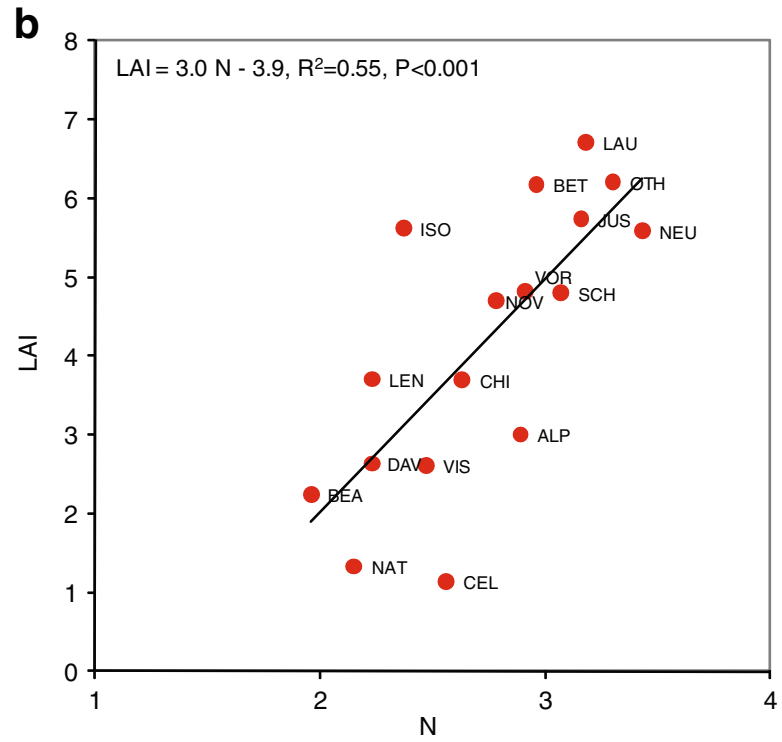

cator values resulted from plot averages per site over all survey years. The regression line is shown 


\section{Discussion}

Sensitivity of diversity and site condition assessments to the survey approach

Species richness increases with increasing sampled area, as illustrated by the species-area curves that are widely used in vegetation ecology (e.g., Rosenzweig 1995). Following this rule, the number of species in the herb and moss layers increased from the $30 \mathrm{~m}^{2}$ plot to the $500 \mathrm{~m}^{2}$ plot at our sites. However, the number of species sampled in the $16 \mathrm{~m}^{2}$ plot was usually higher than the number of species recorded in the $30 \mathrm{~m}^{2}$ plot. This is related to the fact that species richness depends not only on the size of individual vegetation plots (the "grain"), but also on the farthest distance between plots (the "extent") (Palmer and White 1994). Palmer and White (1994) compared the number of species obtained over a given sampling area using various grains, and showed that the aggregation of plots of smaller size resulted in a higher species richness than fewer plots of larger size.

At BEA, DAV, and VOR, the Landolt indicator values obtained from the various vegetation plots did not always agree well with each other. At BEA, the lower agreement between the $500 \mathrm{~m}^{2}$ plot and the other vegetation plots is related to the heterogeneity of the largest plot. The number of species recorded in the $500 \mathrm{~m}^{2}$ plot was much higher than in the 16 quadrats or in the $200 \mathrm{~m}^{2}$ plot. Species such as Rubus idaeus, Galeopsis tetrahit, Fragaria vesca, Epilobium angustifolium, and Sambucus racemosa, all recorded in the $500 \mathrm{~m}^{2}$ plot only, indicate local disturbance. At the same time, part of the $500 \mathrm{~m}^{2}$ plot also covers spots where the stand is denser, with shade-tolerant species such as Blechnum spicant. At VOR and DAV, less than three species were used in the calculations of the indicator values for the $30 \mathrm{~m}^{2}$ plot, which is probably not enough to achieve reliable average indicator values. On the whole, however, the mean indicator values calculated per site, using the species composition of any of our vegetation plots, concurred, which is in line with the results reported by Ewald (2003) and Otýpková (2009). Ewald
(2003) tested how the tightness of the relationship between environmental measurements and Ellenberg's indicator values varied when species of low abundance were randomly omitted from the vegetation records, which resembles sampling smaller vegetation plots. He showed that deleting as many as $40 \%$ of the species records affected the correlations only weakly. Likewise, (Otýpková 2009) found no effect of plot size on the estimated means of Ellenberg's indicator values, even though the smallest plots $\left(1 \mathrm{~m}^{2}\right.$ in grassland, $49 \mathrm{~m}^{2}$ in forests) did not contain more than approximately $50 \%$ of the species recorded in the largest plots ( $49 \mathrm{~m}^{2}$ in grassland, $961 \mathrm{~m}^{2}$ in forests). Yet in the study by Ewald (2003), the lowest number of species before exclusion was 23 . Omitting $40 \%$ of the species thus still left enough species for calculating reliable average indicator values. Similarly, the average number of species in the smallest plots in the study by (Otýpková 2009) was 22.

\section{Temporal changes}

Sørensen's indices of dissimilarity indicated more or less large fluctuations in the floristic composition of the vegetation plots between 1994/1998 and 2003, depending on the site. Dissimilarities between the first and last surveys of the monitoring series greater than dissimilarities calculated for two consecutive survey years, as observed for some of our sites, might indicate significant changes in the mid-term. At sites where the magnitude of dissimilarities between the first and last surveys did not differ from that between consecutive surveys, changes in species composition were probably either related to the short-term internal dynamics of the vegetation community or due to assessment errors.

Sørensen's indices for the period 1999/2001, which corresponds to a change in botanists, were not systematically higher than those calculated for other consecutive surveys. However, at two sites located in the Alps, CEL and NAT, Sørensen's index for 1999/2001 was higher than for any other 
consecutive survey years. At these sites, identification errors may have been somewhat higher than for other sites, as the botanists may have been less familiar with the particular flora of alpine sites compared with that of lowland forests. Fluctuations due to identification errors were probably reduced because the species recorded during the first survey were listed in the field form used for the following one. This may have the drawback of leading to a spurious increase in the number of species recorded in the subsequent surveys, as the observer, as long as the survey is not time-limited, will tend to keep searching for species that he or she may have missed otherwise. Such an increase has been reported, for example, for other European ICP Forests Level II sites. Dupouey et al. (1998; in de Vries et al. 2003a) showed that new species were regularly found during the first 3 years of observation and that the curve plotting the cumulative number of species flattened afterwards. In our data set, we did not observe a systematic increase in the number of species in the second survey. This suggests that our first censuses were rather exhaustive. Two observers were systematically involved in the first survey year, which was shown in other studies to lead to a higher number of species recorded compared with one observer alone (e.g., Kirby et al. 1986; Klimeš et al. 2001). Furthermore, the time spent for each census was not limited, which also contributed to the relative completeness of the species list established during the first survey.

We found a small effect of plot size on the coefficients of variation of the number of species averaged for each plot over all available years, with higher coefficients of variation for the $30 \mathrm{~m}^{2}$ plots compared with the $500 \mathrm{~m}^{2}$ plots. We had actually expected that the number of species might vary less over time on smaller plots compared with larger plots. Consistent with our expectations, Allegrini et al. (2009) found that the pseudoturnover of species, i.e., the changes in species composition due to sampling errors, calculated using censuses made by two teams of botanists on the same plots during a training course, was lower for $0.50 \times 0.50 \mathrm{~m}$ plots than for $10 \times 10 \mathrm{~m}$ plots. They interpreted their findings as a result of greater accuracy in detecting species in the smaller sampling units. Concurring results were found by Archaux and Bergès (2008). Comparing paired values of species richness recorded in 1995 and in 2000 for various vegetation plot sizes (100, 200,300 , and $400 \mathrm{~m}^{2}$ ) at various sites in forests, these authors obtained higher correlations for the smaller plot sizes. On the other hand, Archaux et al. (2007), comparing censuses carried out by four botanists on the same plots at the same time period, found that the repeatability of species richness ( $\%$ of the total variance that is not due to measurement errors) was very high for 2,4 , and $400 \mathrm{~m}^{2}$ plots, with a slight tendency for a higher repeatability for the large plots. The somewhat higher coefficients of variation that we obtained for the $30 \mathrm{~m}^{2}$ plots might be related to the lower average number of species compared with larger plots, as coefficients of variation vary both with the standard deviation and the mean of the population studied.

We could find no clear effect of plot size on the coefficients of variation of Landolt's indicator values averaged for each plot over all available years. We had expected that the values calculated for the $500 \mathrm{~m}^{2}$ plots would be less influenced by random or observer-related fluctuations in species composition than the $30 \mathrm{~m}^{2}$ plots, as larger plots would gather a higher number of species with similar ecological behavior compared with smaller plots. Although Archaux et al. (2007), in the study mentioned above, found no relationship between plot size and the repeatability of Ellenberg's indicator values, Otýpková (2009) reported that the variation in mean Ellenberg's indicator values tended to increase with decreasing plot size. The lack of pattern in our data is probably related to the fact that our coefficients of variation were calculated using censuses repeated over several years rather than within one specific time period. In these conditions, observer-related errors cannot be distinguished from actual changes with time. The degree of change in species composition between two consecutive survey years, as indicated by Sørensen's indices, did not suggest any effect of plot size either. The effect of plot size on assessment errors, if it exists, was masked in our data by the spatial variation of species composition within a site, e.g., due to site heterogeneity or following local disturbance and temporal variation. 
The comparison of the first and last survey of our monitoring series indicated a decrease in Landolt's $R$ value. This suggests that most of our sites have acidified. However, the temporal analysis of all available surveys revealed no significant trend when using linear regression, which suggests that this finding might be related to particular conditions in particular years.

\section{Light and vegetation}

LAI and $L$ were significantly correlated across all sites. The LAI derived from measurements with the Licor LAI-2000 is often referred to as "effective LAI" (e.g., Chen and Cihlar 1996). It is obtained from canopy gap fraction assuming that the foliage spatial distribution is random, which is often not verified in reality, since foliage is actually clumped in most canopies. Effective LAI, however, is a better predictor for radiation interception by plant canopies than the actual LAI (Chen and Cihlar 1996). The positive relationship between LAI and $N$ that we observed within our data set is also in line with studies showing that the LAI of a forest stand is influenced by the availability of nitrogen (Gower et al. 1999). Schleppi (personal communication), comparing modeled LAI and Landolt's indicator value $N$ for approximately 1,000 sites, also found a relationship between these two factors, yet with an apparent decrease in LAI at higher $N$ values. This decrease was ascribed to the correlation of $N$ with the humidity index $F$, whose lowest values (driest sites) and highest values (wettest sites) were associated with lower LAI.

There was, however, no overall relationship between changes in LAI and changes in $L$ (or $N)$ over time. This may be ascribed to the fact that temporal changes in both LAI and indicator values were restricted to a much narrower range compared with the spatial variation of these variables. In addition, light and sky conditions are important when making measurements with the LAI-2000 (a homogeneous sky with no visible sun is required). Shifts in LAI values may thus be due to deviations from ideal conditions. Lastly, annual LAI values may be influenced by the climatic conditions in particular years. At the beech stand of LAU, Graf Pannatier et al. (2007) showed that the annual leaf litterfall, which approximates foliage production, was strongly related to the water regime of the previous year. Year-to-year fluctuations in LAI values may thus be expected, which makes it difficult to assess trends on a longer term when only a few years of measurements are available. The progressive canopy closure suggested by the vegetation changes at ISO was not reflected by an appreciable increase in effective LAI, but several observations support the fact that the already dense canopy closed even more over time: the site remained unmanaged since it was first established in 1995. It was left mostly untouched by storms; the basal area (calculated over the whole 2 ha site) increased steadily between 1994/1995 and 2004/2005, from 30.6 to $33.5 \mathrm{~m}^{2} \mathrm{ha}^{-1}$; lastly, the total cover of the tree layer estimated for the circular plots was and remained high (95-100\%) over the whole measurement period.

In contrast to the site at ISO, NEU was affected first by a large-scale winter storm (Lothar) in 1999 (e.g., Eidg. Forschungsanstalt WSL and Bundesamt für Umwelt, Wald und Landschaft BUWAL, 2001) and then by subsequent local storms, notably in 2001, shortly before the vegetation survey. The vegetation at NEU seemed to react only locally to the opening of the canopy, with an appreciable increase in $L$ being only visible on the $16 \mathrm{~m}^{2}$ plot, although the cover of the tree layer estimated over the circular plots was also reduced following windthrow. The increase in $L$ in the $16 \mathrm{~m}^{2}$ plot was due to two new species, Atropa belladona and Carex pairaei, that appeared in one quadrat only, but that strongly influenced the overall $L$ value because the number of species taken into account for the calculations of the Landolt indicators was very low $(n \leq 3)$. However, photographs of the site and records by field teams both attest to the opening of the canopy and the presence of trees lying untouched quite some time after the storm of 1999. A. belladona and C. pairaei were recorded in 2003 on a quadrat where the otherwise thick litter layer of old leaves was removed in 2001, probably in connection with the disturbance brought about by a falling tree. Most of the other quadrats, as well as the circular plots, were covered by dense patches of 2-year old beech seedlings that de- 
veloped after the mast year of 1999, which was particularly pronounced.

\section{Conclusion}

Although the area surveyed was much smaller in the case of the quadrats, i.e., $16 \mathrm{~m}^{2}$ compared to 30,200 , and $500 \mathrm{~m}^{2}$, the multiple quadrat approach performed well in terms of both species diversity assessment and site characterization by ecological indicator values. It allowed more species to be recorded compared to the Braun-Blanquet relevé carried out in the $30 \mathrm{~m}^{2}$ plot, because quadrats were distributed over an area of roughly $1,850 \mathrm{~m}^{2}$. The multiple quadrat approach is also advantageous with respect to the assessment of small-scale heterogeneity (Kalkhan et al. 2007). Nevertheless, the $500 \mathrm{~m}^{2}$ plot was the most appropriate in terms of diversity assessment, since the number of species in $16 \mathrm{~m}^{2}$ was usually lower than in $500 \mathrm{~m}^{2}$. The $30 \mathrm{~m}^{2}$ plot was clearly too small to capture complete species diversity, but it generally gave satisfactory results in the ecological site classification (for a nationwide comparison, see Wohlgemuth et al. 2008). However, at some of our sites, the number of species present in the $30 \mathrm{~m}^{2}$ plot was too low to allow reliable average indicator values to be calculated. For assessing site conditions, it is thus critical to select a plot size large enough at sites where species richness is low due to e.g. soil acidity or light limitation. Both the $200 \mathrm{~m}^{2}$ and the $500 \mathrm{~m}^{2}$ plot performed well in this respect. This indirectly validates the choice of a common sample area of $400 \mathrm{~m}^{2}$ for all European Level II sites, which was decided within the Expert Panel on Vegetation of ICP Forests in 2002.

There was no clear pattern across the LWF sites regarding temporal changes in the species composition of ground vegetation at the LWF sites, which may have been expected in view of the relatively short period of time considered ( 5 to 9 years). The most significant floristic changes observed at our sites related to changes in light conditions, as already suggested by earlier studies (e.g., Wohlgemuth et al. 2008): canopy closure on the stand scale at one site and local canopy opening due to windthrow at another site. Re- peated vegetation observations appear important in studies that aim to assessing temporal changes. Comparing only the first and last survey of our monitoring series would lead to conclusions which are inconsistent with those of the temporal analysis of all available surveys. While the former comparison indicates an acidification of most of our sites, the latter suggests that this finding might be related to particular conditions (e.g., climatic conditions) in particular years.

Acknowledgements We are grateful to Jürg Buri, Sandra Limacher, Fabienne Progin, Patrick Schleppi, Oliver Schramm, Isabella Sedivy, and Peter Waldner for LAI measurements; to Matthias Dobbertin for providing data on basal areas; and to Peter Jakob and Flurin Suter for the data base support. We thank Ann-Marie Jakob-Murphy for editing the English and two anonymous referees for their valuable comments. We gratefully acknowledge the financial support of the Federal Office for the Environment (FOEN).

\section{References}

Allegrini, M. C., Canullo, R., \& Campetella, G. (2009). ICP-Forests (International Co-operative Programme on Assessment and Monitoring of Air Pollution Effects on Forests): Quality assurance procedure in plant diversity monitoring. Journal of Environmental Monitoring, 11(4), 782-787.

Archaux, F., \& Bergès, L. (2008). Optimising vegetation monitoring. A case study in a French lowland forest. Environmental Monitoring and Assessment, 141(1), 19-25.

Archaux, F., Bergès, L., \& Chevalier, R. (2007). Are plant censuses carried out on small quadrats more reliable than on larger ones? Plant Ecology, 188(1), 179-190.

Archaux, F., Camaret, S., Dupouey, J. L., Ulrich, E., Corcket, E., Bourjot, L., et al. (2009). Can we reliably estimate species richness with large plots? An assessment through calibration training. Plant Ecology, 203(1), 303-315.

Archaux, F., Gosselin, F., Berges, L., \& Chevalier, R. (2006). Effects of sampling time, species richness and observer on the exhaustiveness of plant censuses. Journal of Vegetation Science, 17(3), 299-306.

Braun-Blanquet, J. (1964). Pflanzensoziologie. Grundzüge der Vegetationskunde (3rd ed.). New York: Springer.

Campetella, G., Canullo, R., \& Allegrini, M. C. (20052006). Status and changes of ground vegetation at the CONECOFOR plots, 1999-2005. Annali C.R.A.-SEL, 34, 29-48.

Chen, J. M., \& Cihlar, J. (1996). Retrieving leaf area index of boreal conifer forests using Landsat TM images. Remote Sensing of Environment, 55(1), 153-162. 
Cherubini, P., \& Innes, J. L. (2000). Switzerland: the swiss long-term forest ecosystem research programme. In: J. R. Gosz, C. French, P. Sprott, \& M. White (Eds.), The international long term ecological research network. Perspectives from participating networks (pp. 56-59). Albuquerque, N.M.: U.S. Long Term Ecological Research Network Office, University of New Mexico.

de Vries, W., Reinds, G. J., Posch, M., Sanz, M. J., Krause, G. H. M., Calatayud, V., et al. (2003a). Intensive monitoring of forest ecosystems in Europe. Technical Report 2003, Brussels, Geneva, EC, UN-ECE.

de Vries, W., Vel, E., Reinds, G. J., Deelstra, H., Klap, J. M., Leeters, E. E. J. M., et al. (2003b). Intensive monitoring of forest ecosystems in Europe: 1. Objectives, set-up and evaluation strategy. Forest Ecology and Management, 174(1-3), 77-95.

Diekmann, M. (2003). Species indicator values as an important tool in applied plant ecology-A review. Basic and Applied Ecology, 4, 493-506.

Diekmann, M., Brunet, J., Rühling, A., \& FalkengrenGrerup, U. (1999). Effects of nitrogen deposition: Results of a temporal-spatial analysis of deciduous forests in South Sweden. Plant Biology, 1(4), 471-481.

Dupouey, J. L. , Bourjot, L., Camaret, S., Dobremez, J. F., Forgeard, F., Picard, F., et al. (1998). Study of sampling frequency and comparison of cover estimation methods for ground vegetation assessment. Oxalis Project-EU Project No. 96.60.FR.005.0.

Ellenberg, H., \& Klötzli, F. (1972). Waldgesellschaften und Waldstandorte der Schweiz. Mitteilungen der Eidgenössischen Anstalt für das Forstliche Versuchswesen (EAFV), 48, 587-930.

Ewald, J. (2003). The sensitivity of Ellenberg indicator values to the completeness of vegetation relevés. Basic and Applied Ecology, 4, 507-513.

Gower, S. T., Kucharik, C. J., \& Norman, J. M. (1999). Direct and indirect estimation of leaf area index, $\mathrm{f}(\mathrm{APAR})$, and net primary production of terrestrial ecosystems. Remote Sensing of Environment, 70(1), 29-51.

Graf Pannatier, E., Dobbertin, M., Schmitt, M., Thimonier, A., \& Waldner, P. (2007). Effects of the drought 2003 on forests in Swiss level II plots. In: J. Eichhorn (Ed.), Forests in a changing environment. Results of 20 years ICP Forests Monitoring, Göttingen, Germany (Vol. 142, pp. 128-135), 25-28 October 2006. Schriften aus der Forstlichen Fakultät der Universität Göttingen und der Nordwestdeutschen Forstlichen Versuchsanstalt.

Innes, J. L. (1995). Theoretical and practical criteria for the selection of ecosystem monitoring plots in Swiss forests. Environmental Monitoring and Assessment, 36, 271-294.

Kalkhan, M. A., Stafford, E. J., \& Stohlgren, T. J. (2007). Rapid plant diversity assessment using a pixel nested plot design: A case study in Beaver Meadows, Rocky Mountain National Park, Colorado, USA. Diversity and Distributions, 13(4), 379-388.

Kirby, K. J., Bines, T., Burn, A., Mackintosh, J., Pitkin, P., \& Smith, I. (1986). Seasonal and observer differences in vascular plant records from British woodlands. Journal of Ecology, 74(1), 123-131.
Klimeš, L. (2003). Scale-dependent variation in visual estimates of grassland plant cover. Journal of Vegetation Science, 14(6), 815-821.

Klimeš, L., Dančak, M., Hájek, M., Jongepierová, I., \& Kučera, T. (2001). Scale-dependent biases in species counts in a grassland. Journal of Vegetation Science, 12(5), 699-704.

Landolt, E. (1977). Ökologische Zeigerwerte zur Schweizer Flora. Veröffentlichungen des geobotanischen Institutes der Eidg (Vol. 64). Techn. Hochschule, Stiftung Rübel, Zürich.

Otýpková, Z. (2009). The influence of sample plot size on evaluations with Ellenberg indicator values. Biologia, 64(6), 1123-1128.

Palmer, M. W., \& White, P. S. (1994). Scale-dependence and the species-Area relationship. The American Naturalist, 144(5), 717-740.

Rosenzweig, M. L. (1995). Species diversity in space and time. Cambridge: Cambridge University Press.

Seidling, W. (2005). Ground floor vegetation assessment within the intensive (level II) monitoring of forest ecosystems in Germany: Chances and challenges. European Journal of Forest Research, 124(4), 301-312.

Seidling, W., \& Fischer, R. (2008). Deviances from expected Ellenberg indicator values for nitrogen are related to $\mathrm{N}$ throughfall deposition in forests. Ecological Indicators, 8(5), 639-646.

Sykes, J. M., Horrill, A. D., \& Mountford, M. D. (1983). Use of visual cover assessments as quantitative estimators of some British woodland taxa. Journal of Ecology, 71(1), 437-450.

Thimonier, A., Dupouey, J. L., \& Timbal, J. (1992). Floristic changes in the herb-layer vegetation of a deciduous forest in the Lorraine Plain under the influence of atmospheric deposition. Forest Ecology and Management, 55, 149-167.

Thimonier, A., Sedivy, I., \& Schleppi, P. (2010). Estimating leaf area index in different types of mature forest stands in Switzerland: A comparison of methods. European Journal of Forest Research, 129(4), 543-562.

Tutin, T. G., Heywood, V. H., Burges, N. A., Moore, D. M., Valentine, D. H., Walters, S. M., et al. (1964-1993). Flora Europaea (Vols. 1-5). Cambridge: Cambridge University Press.

van Dobben, H. F., ter Braak, C. J. F., \& Dirkse, G. M. (1999). Undergrowth as a biomonitor for deposition of nitrogen and acidity in pine forest. Forest Ecology and Management, 114(1), 83-95.

Walthert, L., Blaser, P., Lüscher, P., Luster, J., \& Zimmermann, S. (2003). Langfristige WaldökosystemForschung LWF in der Schweiz. Kernprojekt Bodenmatrix. Ergebnisse der ersten Erhebung 1994-1999. E-Collection (Vol. 276). http://e-collection.ethbib.ethz. ch/show?type=bericht\&nr=276. Zürich: Swiss Federal Institute of Technology.

Wilcoxon, F. (1945). Individual comparisons by ranking methods. Biometrics, 1, 80-83.

Wohlgemuth, T., Moser, B., Brändli, U. B., Kull, P., \& Schütz, M. (2008). Diversity of forest plant species at the community and landscape scales in Switzerland. Plant Biosystems, 142(3), 604-613. 